\title{
Circuito Delícias de Pernambuco: a gastronomia como potencial produto turístico
}

\author{
Food Circuit of Pernambuco: a potencial turistic product
}

Isabella Maria Coelho Jarocki ${ }^{1}$

\begin{abstract}
Resumo
Este trabalho tem como objetivo a verificação do Festival Circuito Delícias de Pernambuco realizado em 2006 como potencial produto turístico. O circuito reuniu oito festivais gastronômicos em 7 municípios pernambucanos. Em cada município foi desenvolvido um conjunto de ações de capacitação, mapeamento cultural, desenvolvimento de técnicas culinárias e uso de produtos regionais na elaboração dos pratos participantes. Os resultados foram medidos pela venda de pratos, realização destas capacitações e o registro em livro de todas as receitas elaboradas. Constatou-se que o circuito ainda não é um fator motivador para o deslocamento de pessoas em busca das novidades gastronômicas, mas é potencial componente de produtos turísticos e instrumento de resgate do patrimônio gastronômico local.
\end{abstract}

Palavras-chave: gastronomia; festival gastronômico; alimentação; turismo gastronômico.

\begin{abstract}
The purpose of this study was to investigate the Circuito Delicias de Pernambuco organized in 2006 as a potencial turistic product. The called "circuito" put together 8 festivals within 7 cities. During the eventi it was developed a series of action among workshops, cultural researches and specific trainning for the creation of the recipies in each city. The results were measured from the total sales of plates, number of workshops and the registration of all recipies in a book. It was proved that the "circuito" was not the main factor for the movement of people for the culinary aspects of the city, but it was a component for future turistic products to be planned for the interior of Pernambuco and also a way to value the local culinary patrimony.
\end{abstract}

Keywords: gastronomy; culinary festival; food; gastronomic tourism.

\footnotetext{
1 MA Jornalismo pela University of Arizona. Especialista em Planejamento e Marketing Turístico pela Universidade Católica de Brasília. Especialista em Administração Escolar e Coordenação Pedagógica pela Universidade Federal de Pernambuco. Professora do Curso de Hotelaria da Faculdade Boa Viagem e de Gastronomia da Universidade Salgado de Oliveira. E-mail: isabella@clubsteffano.com.br
} 


\section{Introdução}

As cozinhas e mesas revelam relações sociais, culturais, históricas e econômicas do homem com o lugar que ocupa no tempo e no espaço. Estas relações há muito ignoradas pelos estudiosos, despertam na atualidade especial atenção como objeto de estudo nas ciências sociais, médicas e nas áreas relacionadas à produção, transformação e efeitos do alimento em relação ao meio ambiente e ao homem. A cozinha passou a ser considerada área de interesse da sociedade. A gastronomia é, portanto, um campo de estudos multidisciplinar que merece ser observada.

As primeiras manifestações para os estudos da gastronomia surgiram em 1825, na França com a publicação do livro "Fisiologia do Gosto" de Brillat-Savarin, que trata da interação do homem e da comida e não apenas de receituários. Desde então, são inúmeras as publicações sobre a comida como objeto de estudos, especialmente nas áreas humanas. Só no início do século XX, áreas como a antropologia, a história, a sociologia e a nutrição consideraram a alimentação para desenvolver estudos dos hábitos, costumes, simbolismos, consumo, estilo de vida, a saúde e a fome do homem.

A seriedade e mesmo o ineditismo destes levantamentos multidisciplinares despertaram interesse pelo que saía das cozinhas e registrou verdadeiros inventários do que se produzia na indústria, onde, como e quando se plantavam frutas, verduras, cereais e quais eram as preparações festejadas em cidades e localidades. Enfim, despertou não só os estudos científicos, mas a possibilidade de utilizar a gastronomia como negócio também em diversos setores da economia. Destaca-se o turismo um destes setores, por justamente reunir instrumentos e ferramentas necessários para suprir as necessidades básicas do ser humano de comer, dormir, comercializar e se deslocar em busca de novos conhecimentos, espaços e, sobretudo, lazer.

O turismo passou então, a integrar este universo multidisciplinar da gastronomia enquanto objeto de estudo e negócio provocando diversos desdobramentos, em sua maioria de ordem prática e comercial. Afinal o turismo é um meio integrador entre os povos e um meio de identificar e criar oportunidades para a divulgação das características mais profundas de uma cultura. Afora isto, é elemento importante para o desenvolvimento sustentável nas áreas rurais e de baixa renda, pois tem ferramentas para promover a inclusão social.

Um exemplo claro da união entre turismo e gastronomia se passou no Brasil dos anos 70 do 
século passado com a chegada de chefes estrangeiros que se instalaram nas cozinhas das grandes redes hoteleiras do Rio de Janeiro e São Paulo impulsionados pelo fluxo de turistas internacionais. Estes chefes inspirados pelos preceitos da francesa Nouvelle Cuisine, que defendia o uso de produtos locais, juntaram a secular técnica francesa às frutas brasileiras como a goiaba e o maracujá, já inventariadas no receituário brasileiro, e batizaram com novo status os alimentos comerciais brasileiros. A novidade estimulou estes chefes a organizarem festivais gastronômicos, que se tornaram atrações locais e geraram o desejo de experimentar. Constatar que os festivais gastronômicos podem se tornar além de atrações, produtos turísticos e instrumento de resgate de patrimônio inspirou este trabalho, que coloca em evidência o festival como uma forma de provocar o deslocamento de pessoas para um destino em busca de sua gastronomia. O objeto de estudo não estará limitado a um festival, mas um evento previamente organizado pelo Sebrae, envolvendo oito festivais no Estado de Pernambuco em 2006 e nomeado de Circuito Delicias de Pernambuco. Analisar o Circuito como potencial produto turístico para Pernambuco é o objetivo geral deste estudo. São, portanto, objetivos específicos a verificação dos resultados do Circuito Delícias de Pernambuco junto aos proprietários de restaurantes pela venda de pratos em cada festival; verificar por meio das receitas o uso de produtos alimentícios e artesanais; constatar a realização de cursos para capacitação do segmento local, verificar os resultados por meio da publicação de livro inventário dos festivais como forma de registro de oferta turística de cada localidade.

A alimentação é um dos componentes da demanda turística e por isso deve ser tratada como de suma importância para a prestação de serviços ao turista e desenvolvimento econômico de uma localidade. Já não era sem tempo que a gastronomia fosse incluída nas feiras e representações oficiais brasileiras já que divulga e valoriza a identidade cultural de um povo. É patrimônio. Isto sem contar, que além de ser essencial, pois o turista tem que satisfazer a fome, faz parte e toma lugar essencial nos momentos de lazer e entretenimento.

Em 2003, segundo o relatório do Instituto Brasileiro de Geografia e Estatística (IBGE), o setor de alimentação representou 2,4 \% do PIB brasileiro, empregando 6 milhões de pessoas em todo o país. São cerca de um milhão de pequenas e micro-empresas constatando um crescimento de $12,5 \%$ ao ano no segmento de alimentação fora do lar. O setor se torna cada vez mais forte na atração de negócios de setores adjacentes, por ser um respeitado gerador de empregos e elemento de inclusão social dado a sua ampla abertura para entrada de 
profissionais não qualificados. Vê-se então que cabe à gastronomia encontrar meios de difundir a culinária, valorizar sua identidade cultural e promover o desenvolvimento sustentável. Os festivais podem ser uma destas formas de concretização. O tema, portanto, que relaciona gastronomia com o turismo se justifica nos estudos das sociedades modernas e comprova a relevância da geração de produtos turísticos envolvendo e impulsionando a culinária e conseqüentemente a valorização da cultura.

Considerando o Circuito Delícias de Pernambuco como evento inédito que utilizou como objetivos para sua realização a valorização da gastronomia e a qualificação de pessoas para o turismo, será utilizado o estudo de caso e a avaliação empírico-analítica como metodologia através da utilização do levantamento de resultados de vendas de pratos, entrevistas e avaliações dos agentes envolvidos.

O capítulo inicial será dedicado a um breve histórico da comida através dos períodos históricos enfocando a cronologia dos principais fatos que contribuíram para o nascimento da gastronomia como fator não só de sobrevivência, mas também de convivência entre os homens. É dedicado ainda no final do capítulo, um espaço para a gastronomia pernambucana, como pano de fundo do tema dos festivais reunidos pelo Circuito Delícias de Pernambuco. Vale um destaque para o estado canavieiro de Pernambuco como palco para a formação de uma cultura gastronômica voltada para o açúcar e para seus elementos formadores: o português, o negro e o índio.

A convivência desperta o desejo de conhecer sempre o novo, resgatar o velho e valorizar os consagrados. Discute-se a seguir justamente os desejos do homem de se conectar com as novidades do paladar através da interface entre gastronomia e turismo partindo de um resgate histórico de cada localidade. Iniciando-se pelos guias turísticos, que foram os primeiros instrumentos de divulgação para o viajante do comer fora de casa em estradas e outras localidades. Em seguida, faz-se uma discussão sobre a importância dos festivais gastronômicos sob o enfoque comercial e histórico-cultural, e por fim, os fatores que levaram a formatação de um Circuito Gastronômico para estado de Pernambuco a fim de resgatar o patrimônio culinário e construir um produto turístico.

Nos últimos capítulos são apresentadas a metodologia e formatação do Circuito Delícias de Pernambuco. Por fim, serão apresentados os resultados quantitativos do evento e propostas para o aperfeiçoamento do Circuito Delícias de Pernambuco como produto turístico para os 
anos seguintes, tais como sua ampliação das ações para a hotelaria e o resgate de preparações tradicionais.

\section{A Gastronomia Através dos Tempos}

O início da história das civilizações está relacionada com a procura do alimento para sobrevivência. Nômade, na pré-história, o homem era um coletor de alimentos: frutas e raízes, caça e pesca. A descoberta do fogo transformou o cotidiano do homem e o distinguiu dos outros animais. De acordo com Fernandez-Armesto (2004) "a cultura começou quando o que era cru foi cozido". Ao cozinhar, o homem identificou sabores, temperaturas, proteção, a preservação do alimento e sobretudo, a importância da organização da sociedade. Acontecia a primeira revolução social.

$\mathrm{O}$ ato de cozinhar não é apenas uma forma de preparar o alimento, mas também uma maneira de organizar a sociedade em torno de refeições em conjunto e de horários de comer previsíveis. Ele introduz novas funções especializadas de prazeres e responsabilidades compartilhados. (FERNANDEZ-ARMESTO, 2004, p.24).

A segunda grande revolução na história da alimentação aconteceu com a descoberta da função das sementes. A semente plantada germinaria, dando origem a uma nova planta e a possibilidade de permanência. Era o início de uma nova forma de viver. O homem se fixou à terra e de coletor passou a ser produtor do seu alimento. Ao evitar os deslocamentos diante da agricultura, veio o tempo livre para a criação. Surgiram os utensílios, o mobiliário e a busca por novas formas de preparar o alimento, de domesticar e criar animais e sobretudo, de observar a natureza e sistematizar o cotidiano. A alimentação ficou mais variada, o alimento passou a ser preparado com antecedência em horários determinados, abriu-se espaço para os rituais e para o intercâmbio com grupos vizinhos. (LEAL, 1998).

Alguns autores como Fernandez-Armesto (2004) e Carneiro (2003) consideram que a conquista dos alimentos através da sua coleta, produção e controle conduziu a privilégios, ou seja, a uma diferenciação social a partir do que se comia. $O$ ato de comer passou a ser prazeroso e sinalizador de poder. Talvez o primeiro indicador desta distinção de classes tenha 
sido a quantidade de comida consumida. Estudos demonstram na análise de restos mortais de uma mesma comunidade níveis diferenciados de nutrição de acordo com a posição social ocupada.

A quantidade era mais importante que a qualidade. Um apetite gigantesco normalmente era uma fonte de prestígio em quase todas as sociedades, em parte como sinal de força, e em parte, talvez pela indulgência acessível apenas aos ricos. (FERNANDEZ -ARMESTO. 2004, p.162).

Por outro lado, o excesso de alimentos nos banquetes reais na antiguidade alimentava os pobres. Os banquetes claramente apontavam a comida como sinalizador de classe social, pois o Estado funcionava como armazenador de produtos para distribuição em tempos de fome. Os banquetes que podiam durar até dez dias, além de reforçar alianças políticas e propiciarem momentos de discussões filosóficas, eram uma forma de distribuir alimentos para os pobres, embora muitas vezes obedecessem a critérios hierárquicos determinados pelos governantes em relação a quantidade e qualidade dos alimentos.

Na Idade Média com a destruição das cidades e a formação dos feudos ocupando áreas rurais a formatação da distribuição dos alimentos não foi modificada, evidenciando ainda mais a forma heróica do comer como modelo de comportamento e de poder. Praticamente as relações comerciais através de moeda desapareceram, e as relações passaram a ser entre senhores feudais e servos numa relação de obediência e produção agrícola em troca de proteção e alimento dentro de grandes propriedades rurais. Os banquetes da nobreza medieval permaneceram, mas o núcleo do desenvolvimento da gastronomia até o século XV passou a ser nos mosteiros, que não deixavam de ser território da nobreza, mas cumpriam a função social da evangelização dos servos. O aperfeiçoamento da produção vinícola e de bebidas, bem como de novas culturas, se deu dentro destas fortalezas da Igreja Católica sob os preceitos das tradições greco-romanas em relação a comida de qualidade.

De acordo com Leonor (1998) os monges enriqueceram a qualidade dos alimentos através da simplificação das preparações, de técnicas de conservação e a sistematização da produção dos alimentos como a padaria comunitária. Por estarem presentes em quase toda a Europa, os mosteiros se tornaram centros de armazenamento de alimentos e local para hospedagem com mesa farta e saudável. Pode-se dizer que os mosteiros reativaram as feiras, que se tornaram o grande evento social e comercial, pois marcavam a reunião de mercadores, camponeses e 
cantadores, que além de vender comida, sedas e especiarias divertiam a população. Fora dos mosteiros, no entanto, imperava o excesso de condimentos e a justaposição dos alimentos sem critérios de combinação ou qualidade.

Um novo impulso à gastronomia só aconteceu a partir do século XV com o intercâmbio de produtos e culturas provocados pela investida de navegadores europeus a novos mundos em busca de especiarias no oriente e do cobiçado e nobre açúcar. O renascimento e o aparecimento dos restaurantes também modificaram as formas de alimentação na idade moderna. Este período da história trouxe para a gastronomia novos prazeres, a preocupação com a estética e a mudança de hábitos em toda a Europa diante da introdução de produtos vindos do oriente e das Américas, e ainda da valorização do chefe de cozinha no continente. Embora os italianos tenham se destacado na preparação de guloseimas graças à herança greco-romana, a gastronomia encontrou o seu desenvolvimento na França. Em 1765, contrariando regulamentações do comércio parisiense, foram criadas em Paris por um taverneiro conhecido por Boulanger, as sopas restauradoras para recuperar as forças de pessoas debilitadas. Estes restaurantes, como a princípio eram chamadas as sopas, foram o marco da queda das rígidas corporações de ofício francesas e deu início a uma nova atividade comercial que revolucionaria a alimentação. O restaurante de uma sopa se transformou em local de encontros de pessoas debilitadas à atração turística e ponto comercial.

Entre as inovações, o restaurante possibilitava que as pessoas se reunissem para comer juntas, mas sem a necessidade de dividir a mesma comida. A introdução do cardápio para escolha dos pratos com a inclusão dos preços, permitia que o comensal calculasse a conta e o pagamento passou a ser individual. O espaço para as refeições também foi modificado pelo restaurante com salas individuais para até oito pessoas, diferente dos cafés já existentes e das grandes salas comuns da hospedarias, onde se utilizava o table d'hote. O restaurante era um espaço publicamente privado com horários mais extensos.

A nova instituição restaurante e os efeitos da revolução francesa despertaram o lado empreendedor de vários cozinheiros que trabalhavam para a aristocracia, banida de Paris. Estes cozinheiros montaram os seus restaurantes. Um exemplo é Antoine Beauvilliers que montou o primeiro restaurante de luxo de Paris - La Grande Taverne de Londres - nas arcadas do Palais Royal. Os restaurantes inauguraram o sistema de alimentação moderno, regras de comportamento em público e a nova profissão reconhecida de chefe de cozinha. O primeiro relato sobre a gastronomia surgiu também nesta época elaborado por Brillat-Savarin, 
intitulado Fisiologia do Gosto em 1825, que tratava das relações entre o homem e a comida. E o desenvolvimento deste novo negócio não parou. Estimulados pelos movimentos de deslocamentos de pessoas pela Europa e pelo crescimento do número de restaurantes, chefes franceses como Antoine Carême (1783-1833) e Auguste Escoffier (1646-1935) sistematizaram, cada um a seu tempo, a alta gastronomia francesa, chamada de Haute Cuisine em manuais de técnicas culinárias até hoje perseguidas pelos que atravessam as portas das cozinhas profissionais. No final do século XIX, Paris tornara-se o centro da gastronomia com cafés e restaurantes espalhados pelas grandes avenidas. Outro momento interessante no desenvolvimento da gastronomia aconteceu da sociedade de César Ritz e do Chef Auguste Escoffier. Ritz, hoteleiro, convidou Escoffier para ser o chefe do hotel do Grand Hotel de Monte Carlo e do Savoy de Londres. Estava inaugurado o setor de alimentos e bebidas de um hotel. Na virada do século XIX para o século XX, já existiam em Paris cerca de 3 mil restaurantes entre antigas tabernas e luxuosos estabelecimentos.

Os restaurantes e eventos relacionados ao deslocamento de pessoas com a expansão das estradas de ferro, bem como com as inovações em equipamentos e metodologia de produção promovidas pela revolução industrial, prosperaram e modificaram a vida das pessoas e conseqüentemente sua forma de comer. Para Romio (2000) em sua descrição sobre a evolução da gastronomia através dos tempos, coloca de forma interessante o papel das guerras e revoluções em relação a gastronomia.

Ao longo da história da humanidade, às guerras e revoluções pode-se acreditar, ainda que de maneira indireta, promoveu avanços consideráveis na arte do sabor culinário. (ROMIO, 2003. p.177).

Assim as guerras também não conseguiram driblar a fortaleza dos hábitos alimentares de um povo, ao contrário terminaram por fortalecê-los diante de ameaças e da entrada de novos produtos. Como foi o caso da Nouvelle Cuisine, movimento culinário surgido na França em meados da década de 70 do século passado. Entre os preceitos da Nouvelle Cuisine estava a valorização dos produtos locais, oposição às técnicas complicadas de preparo, redução dos tempos de cocção, uso de ingredientes frescos, rejeição de menus extensos, interesse pelas cozinhas regionais, receptividade com relação às novas técnicas e equipamentos, criatividade e valorização estética na apresentação dos pratos. 
O final do século XX, no rastro da Nouvelle Cuisine, foi invadido por diversas correntes culinárias que mais uma vez representavam as novas formas de vida das pessoas nos centros urbanos. Entre elas, a saída da mulher de casa, ou melhor, das cozinhas para o mercado de trabalho; os tempos de trabalho reduzindo os horários das refeições em casa, a exploração imobiliária diminuindo os tamanhos das cozinhas nos apartamentos e os equipamentos e utensílios aprimorando técnicas e facilitando o manuseio de produtos e preparações culinárias.

Neste contexto, nasceram o Fast Food, ou comida rápida, encabeçada pelos norte- americanos e seus famosos hambúrgueres e hot dogs. Não há questionamento de que o formato é bem sucedido, pois se espalhou por todo mundo, até em redutos gastronômicos tradicionais como a capital francesa. Para muitos chefes tradicionais, este movimento representado pela rede McDonald's em todo o mundo não atrapalha o crescimento da culinária tradicional, apenas complementa e auxilia o cotidiano das pessoas. Mas já são constantes os questionamentos em relação a contribuição dos Fast Food para o desenvolvimento de hábitos alimentares pouco saudáveis. De acordo com Algranti (2006) milhões de pessoas estão acima do peso em todo o mundo e um dos vilões apontados são os restaurantes Fast Food que têm como características conjugar a rapidez e preços mais acessíveis à pouca preocupação com qualidade dos produtos.

Até um movimento denominado Slow Food surgido na Itália veio em oposição política ao império dos Fast Food. O Slow Food é atualmente uma organização sem fins lucrativos que tem como objetivos preservar os alimentos para o corpo e para alma. Mas o final do século, ao mesmo tempo que demonstrava através de seus restaurantes a mudança de vida das pessoas, identificando a falta de tempo e a importância da saúde - deixou claro o movimento cíclico da alimentação. Há o retorno aos primórdios da instituição restaurante quando são criados os restaurantes Fast Food para atender uma nova forma de vida e ao mesmo tempo surge novamente a preocupação com a saúde das sopas restauradoras para a valorização dos alimentos saudáveis do Slow Food.

O novo século e milênio trazem a ratificação da culinária globalizada e sem fronteiras do mundo virtual através de correntes como a da cozinha molecular, a Fusion Cuisine e a Confort Food. Em comum, a inquietação com as formas do comer tradicional e com a recuperação dos sentidos e sentimentos humanos através da comida. Comer passou a ser um mistério na forma e no conteúdo. Para definir esta nova arte de fazer gastronomia, Algranti (2006) assim coloca: "Trata-se de um prazer quase espiritual. A grande aventura do desejo gustativo." 
Desta forma a cozinha molecular do espanhol Ferrán Adriá, é também chamada de cozinha do espetáculo. Segundo seu manifesto lançado no evento Madrid Fusión em janeiro de 2006 - " $a$ cozinha é uma linguagem através do qual se pode expressar harmonia criatividade, felicidade, beleza, poesia, complexidade, magia, humor e provocação.” Parte do ano, Adriá e sua equipe passam em laboratórios químicos na criação de receitas surpreendentes e divertidas e o resto do ano no restaurante El Buli na Espanha ensinando as pessoas a comer em colheres sorvetes que explodem em pelo menos 20 pequenas porções que compõem a refeição ao invés dos tradicionais menus degustação onde constam entrada, prato principal e sobremesas. Ir a um restaurante de cozinha molecular é uma experiência turística.

A surpresa é também parte dos chefes que adotaram a Fusion Cuisine que buscam não a surpresa dos produtos, mas a surpresa das combinações de produtos e de culturas. Nos cardápios de Fusion Cuisine pode-se encontrar crepe de jerimum nordestino com mascarpone italiano, ou um creme brûllée francês com toques das frutas brasileiras. Já o Comfort Food vai em busca das preparações e produtos do cotidiano, mas que proporcionam conforto e lembranças de tempos e pessoas queridas. Mesmo sem ter adeptos comerciais traduzidos em restaurantes como a Cozinha Molecular e a Fusion Cuisine, a filosofia da Comfort Food está presente nas duas segundo bem define Santos (2005) "estas são comidas da alma." E são justamente as comidas que não se esquece em um determinado momento da vida, que os movimentos das cozinhas regionais, vem tentando resgatar como patrimônio e como incentivador de produtos turísticos. É a valorização dos produtos regionais na sua forma de fazer, plantar e registrar momentos independentes de corrente culinária.

Como se pode constatar é possível reconstituir histórias inteiras de uma civilização através das cozinhas e hábitos alimentares. De acordo com Carneiro (2003) é impossível falar de uma história da alimentação sem levarem-se em conta os aspectos da história social, econômica e cultural de um povo. Vale lembrar que o estudo da história da gastronomia vem sobretudo ajudando no resgate das formas mais simples do comer de cada sociedade, não como uma forma de retrocesso ou intransigências, mas como parte de um ciclo natural de idas e vindas comuns à arte e justificada pelas ciências em prol do homem e do seu futuro.

\subsection{Gastronomia pernambucana}

O antropólogo pernambucano Gilberto Freyre considera que a formação do povo brasileiro é um processo de equilíbrio de antagonismos do europeu, do índio e do africano, do herege e do 
católico, do bacharel e do analfabeto, do senhor e do escravo, dos que comem e dos que não comem. Sobre a gastronomia dos que não comem, ou seja a gastronomia da fome, pois afinal o campo da gastronomia vai da fome à gula, outro pernambucano Josué de Castro, revelou em seu livro "Geografia da fome", mas um aspecto do brasileiro, especificamente do nordestino: a sua eterna relação com a seca, com o sofrimento e com a morte. Josué de Castro não "via a fome como a falta de alimentos, mas pelos resultados de relações sociais, responsabilidade pura e exclusiva da ação política dos homens". Chamava atenção não só para o aspecto fisiológico da fome, mas para o seu aspecto de sensação interna.

Outro nordestino Luiz da Câmara Cascudo (2004) na sua História da Alimentação no Brasil descreve com beleza nossas superstições alimentares quase sempre de origem portuguesa, fala também das cantigas, das frutas e da hospitalidade brasileira sempre acentuando o aspecto das tradições populares. Segundo Cascudo (2004) "para o povo não há argumento probante, técnico ou convincente contra o paladar." E ainda:

(...) em momentos rituais ou cerimoniais o alimento é um elemento fixador psicológico no plano emocional e comer certos pratos é ligar-se ao local ou a quem o preparou. (CASCUDO, 2004. p, 204)

Ainda sobre os autores brasileiros que trataram da gastronomia como revelação de uma sociedade, vale citar outra obra de destaque de Gilberto Freyre, o livro Açúcar publicado pela primeira vez em 1939, a qual oferece grande contribuição para o entendimento da identidade nacional, em especial a pernambucana, a partir da civilização do açúcar no Brasil, a chamada "sacarocracia". São os doces que revelam mais uma vez a troca de idéias nas cozinhas dos engenhos entre as sinhás, negras e índias. A constituição da culinária pernambucana, portanto, passa obrigatoriamente pelos três povos. Em algumas localidades esta trilogia é substituída, ou acrescida de outras culturas, como no sul do país com os italianos, japoneses e alemães.

Em Pernambuco, a chegada do açúcar em torno de 1526 trouxe com ele a casa grande e a senzala, a sinhá e a negra, a negra e a índia nas cozinhas e terreiros para a mistura das receitas, dos temperos e dos sabores e construir uma culinária doce, ensopada, condimentada, colorida. Uma culinária equilibrada, sem o predomínio das 3 tradições de sua formação. Com os fundamentos da cozinha portuguesa graças a sua maleabilidade de adaptação inicial, a gastronomia, especialmente a pernambucana, tem no bolo de rolo, na cartola e macaxeira com 
charque, no bode nos cozidos e nas peixadas, memórias deste passado formador que continua marcado do litoral ao sertão do estado.

\subsection{Gastronomia e cultura}

É interessante a intensificação dos estudos relacionados à gastronomia no Brasil a partir de meados dos anos 70 do século XX no Brasil. Os primeiros indícios de uma nova abordagem da gastronomia como ciência e arte ficaram evidentes com a chegada das grandes redes hoteleiras internacionais que trouxeram chefes vestidos de branco e uma parafernália de facas e utensílios na bagagem, até então, desconhecidos do empresário do segmento.

A partir de então, as cozinhas dos restaurantes dos principais destinos turísticos brasileiros passaram a ser baseadas não mais apenas em produtos ou sabores, mas, sobretudo, comandadas pelas técnicas e a gestão do cozinhar. Técnicas que se aprendem nas escolas especializadas em culinária. Em conseqüência desta expansão da gastronomia na hotelaria, surgiram escolas para formação de mão de obra na área, os serviços passaram a buscar requisitos da qualidade, os cardápios se renovaram, a entrada de grandes redes de alimentação internacionais chegaram, o mercado editorial especializado cresceu e o mais interessante: houve a busca e o resgate pela comida brasileira e pela sua ligação a hábitos e valores. $\mathrm{O}$ interesse chegou ao turismo. Por outro lado, e levando em consideração a idéia que parece mesmo um paradoxo, a chegada de chefes estrangeiros provocou a valorização dos produtos nacionais, pois os chefes de formação costumam se basear no conceito de "terroir" que quer dizer: de valorização dos produtos do lugar, da terra. Instalou-se então, a alta gastronomia brasileira e a retomada da culinária regional.

As primeiras manifestações desta nova era para os restaurantes brasileiros foram os cardápios desenvolvidos por estes grandes chefes, que adotaram o Brasil como Claude Troigross e Laurent Suaudeau. Utilizaram e abusaram dos produtos brasileiros na confecção de grandes sucessos da mesa internacional. Quem antes dos 70's imaginaria um mousse de maracujá, jilós caramelizados e purê de feijão verde? Laurent Suaudeau em seu livro, "Cartas a um jovem chef' (2006) enfatiza que:

A alimentação deve ser vista como um conceito cultural, do mesmo modo que a língua, os costumes, as festas, mais tradicionais de um povo. Comecei isto não na França, meu país de origem, mas aqui no Brasil. (SUAUDEAU, 2006. p.10) 
É a descoberta da gastronomia como cultura e por ser cultura possível de ser organizada como produto, como atração, como patrimônio, como turismo. Por produto turístico entende-se um composto de atividades e serviços relacionados com alojamento, alimentação, transportes, artesanato e todas as atividades ligadas a atrações culturais e naturais. O produto turístico estrutura-se, portanto, como um complexo articulado de componentes que se conjugam e operam no sentido da satisfação do turista pela prestação de uma cadeia organizada de serviços que garantem globalmente a recepção e acolhimento dos turistas e visitantes.

O turismo gastronômico favorece, portanto, o desenvolvimento e especialmente o fortalecimento de roteiros turísticos por estar diretamente integrado ao turismo cultural e ao patrimônio. No caso do Circuito Delícias de Pernambuco, centro deste estudo, a intenção era a de atrair o turista pelas novidades gastronômicas que seriam apresentadas pelos restaurantes participantes em cada localidade provocando deslocamentos para município.

O Circuito Delícias de Pernambuco tinha como principais objetivos apresentar uma proposta para o desenvolvimento da gastronomia para o Estado de Pernambuco, a fim de ampliar a visibilidade e diversidade da culinária pernambucana e provocar o desenvolvimento e aperfeiçoamento dos negócios de alimentação. Acreditava-se que a iniciativa aumentaria o fluxo de turistas nos municípios e conseqüentemente nos restaurantes participantes e ainda fortaleceria o conceito de patrimônio gastronômico. A vontade de conhecer novas culturas inclui a curiosidade pelos novos sabores e alimentos. Une o turismo e gastronomia. É interessante lembrar que a gastronomia está ligada ao prazer, a eventos familiares e, sobretudo às lembranças como o turismo.

O Circuito Delicias de Pernambuco reuniu em um grande evento 8 festivais gastronômicos durante o ano: de abril a novembro de 2006. Participaram os municípios de Caruaru, Garanhuns, Gravatá, Porto de Galinhas, Serra Talhada, Petrolina e Recife, este com 2 festivais. Entre as intenções do circuito estava a consolidação ou a tentativa da confirmação de Pernambuco como o terceiro pólo gastronômico do país. O modelo de festival gastronômico previsto para o Circuito Delícias de Pernambuco não previa o trabalho e o desenvolvimento de outros componentes de um produto turístico como a hospedagem, transporte e organização de outras atrações que poderiam ser conjugadas a arte de comer fora e experimentar novas receitas. 


\subsection{A interface gastronomia e turismo}

Desde os primórdios do turismo europeu, houve a tentativa de direcionar os viajantes para um determinado local ou produto. Talvez não houvesse a intenção clara que hoje se percebe em todo o marketing em torno de produtos turísticos, mas havia a consideração determinada da promoção do deslocamento organizado de pessoas (GREGSON, 2005). Talvez a documentação que seja mais abrangente na aproximação do turismo com a gastronomia sejam os guias turísticos. A primeira forma de divulgação obedecendo este formato data de 840 , através do Guides Joanne, onde eram mencionadas apresentações geográficas e históricas, mapas e conselhos aos viajantes (RIBEIRO, 2006). Contudo, os detalhes relacionados à gastronomia só começaram mesmo a aparecer com o advento da indústria automobilística e a abertura de estradas por toda a Europa, sugerindo paradas para refeições e descanso.

Em 1901, a empresa de pneus Michelin vendo a perspectiva do crescimento da indústria automobilística e desenvolvimento dos centros urbanos, inovou ao lançar o Guide Michelin pour lês chauffeuers et lês vélocipédistes. Utilizando o formato de dicionário das localidades, continha indicativos de postos de venda da Michelin, oficinas e ainda itinerários, hotéis e restaurantes. A princípio eram apenas indicações de onde comer, mas a partir de 1920, passaram a figurar recomendações do que comer. Outros guias se seguiram como o Guide bleu bords de Loire et Sud, que introduziram seções exclusivas com especialidades gastronômicas e principais vinhos de cada região da França a partir de 1930.

A integração entre turismo e gastronomia firmava-se obedecendo aos princípios fundamentais de deslocamento, descanso, lazer, compras, e alimentação. Hoje os guias e os roteiros com indicações e avaliações são parte obrigatória no material de divulgação de uma localidade. Não se pode afirmar ao certo que a gastronomia seja um fator determinante para o deslocamento de pessoas. Segundo Ribeiro (2006), os recursos gastronômicos que as cidades brasileiras oferecem ainda não foram planejados para o desenvolvimento do turismo. Isto é, as pessoas visitam as cidades por algum motivo e a culinária sempre é colocada como um complemento do passeio e não como objetivo desencadeador da viagem ou do deslocamento como acontece na Europa.

Existe a intenção de transformar a culinária local não só em complemento, mas em fator desencadeante de um deslocamento. Seria a sistematização de um produto turístico a partir da culinária. Talvez tenha sido este um dos motivadores da organização de festivais 
gastronômicos.

Os hotéis foram a porta de entrada para a alta gastronomia em território brasileiro e com ela o despertar para valorização da gastronomia brasileira. A melhor forma encontrada pelos chefes estrangeiros que imigraram para o Brasil foi então, a organização de eventos gastronômicos em que se mesclavam técnicas culinárias com a riqueza dos produtos e preparações da cozinha brasileira. Os festivais estão relacionados com a geração do fator motivação e da sustentabilidade que garante a continuidade do evento e sua consolidação. Em geral, no caso dos festivais gastronômicos os visitantes são pessoas residentes na cidade sede do evento ou em cidades próximas gerando expectativa na população. E é esta expectativa e sua divulgação que vai transformando um evento em sucesso e atraindo novos negócios e outro público. Os festivais gastronômicos mais comuns acontecem em locais com acesso restrito ao público e cobrança de taxa de ingresso ou então, em restaurantes de hotel vinculados ao consumo restringindo a participação de boa parte da população.

No Brasil, para que se atingisse um número de participantes maior, os eventos gastronômicos começaram a tomar novos rumos agregando ao sabor dos pratos atrações culturais e artísticas. É o caso do festival internacional de cultura e gastronomia de Tiradentes em que famosos chefes internacionais promovem almoços e jantares, homenageiam personalidades da cultura brasileira e divulgam produtos e artesanato brasileiro. Outros festivais como os promovidos pela Associação dos Pratos da Boa Lembrança promovem um intercâmbio de chefes de uma região para outra, desafiando-os a trabalhar em cozinhas locais. O mais recente tipo de festival promove a criação de pratos pelos restaurantes às vezes com temas pré-determinados, e que ficam em evidência nos cardápios durante o tempo do festival. Neste último participaram restaurantes de todo o tipo e oferecendo pratos de sabores e preços variados. Foi o formato escolhido pelo Circuito Delícias de Pernambuco e também pelo Brasil Sabor promovido em 2006 pela Abrasel (Associação Brasileira de Bares e Restaurantes).

O Festival Brasil Sabor merece ser citado por ter sido considerado em 2006, o maior festival gastronômico do planeta. O festival foi também, como no caso do Circuito Delícias de Pernambuco, uma junção de festivais que ocorriam em diversos estados brasileiros. Com o apoio do Ministério do Turismo e do Sebrae, o evento reuniu durante trinta dias 1.057 restaurantes em 70 cidades de 24 estados brasileiros e comercializou mais de 100 mil pratos. Para o festival Brasil Sabor 2006 foram produzidos 600 mil guias de restaurantes, 300 mil tabelas da Copa do Mundo, 540 mil encartes nos jornais Folha de São Paulo e Estado de São 
Paulo, além de uma ampla divulgação nacional na Rede Globo de Televisão. O festival foi um marco na história da gastronomia brasileira.

É verdade que os festivais nos três formatos acima citados estão conseguindo difundir a culinária brasileira através do estímulo à criação de pratos e cardápios com uso de produtos regionais típicos, bem como o resgate de preparações familiares e de comidas de rua brasileiras. Estão resgatando o patrimônio gastronômico, mas será que estão conseguindo atrair o visitante?

\section{Circuito Delícias de Pernambuco: o festival}

O Circuito Delícias de Pernambuco partiu da idéia de unir os festivais gastronômicos que já aconteciam no estado de Pernambuco em um único evento. O Circuito foi trabalhado em comunhão com o Sebrae - órgão de fomento e capacitação do empresariado - e da Associação Brasileira de Bares e Restaurantes - Abrasel além de parceiros comerciais e institucionais em cada localidade. Até 2005, eram realizados festivais gastronômicos isolados como o Recife Sabor e o Festival Gastronômico de Pernambuco em Recife, o Festival das Flores em Garanhuns e outros poucos eventos estruturados em Gravatá e Serra Talhada. Todos os festivais eram organizados localmente pelos governos municipais, entidades de classe, empresas de eventos e tinham em comum o patrocínio do Sebrae. A iniciativa de unir todos os festivais em um circuito anual partiu, por conseqüência, do Sebrae Pernambuco numa opção institucional de evidenciar as ações dedicadas ao setor de alimentação.

Ao mesmo tempo, defendia-se que a criação de um circuito organizado provocaria o fortalecimento e a visibilidade da gastronomia em Pernambuco, além de promover a melhoria dos serviços de alimentação nas cidades do interior através da capacitação do empresariado e equipes. Era uma forma também de fomentar o desenvolvimento do segmento de bares e restaurantes no interior do estado e combater a sazonalidade, mais evidente nas cidades de veraneio contribuindo diretamente para o turismo.

Para a realização do programa de capacitação, o Sebrae se aliou a parceiros como Senac, para o desenvolvimento de cursos para garçons, a Abrasel, para implantação do programa Qualidade na Mesa para capacitação dos empresários em Técnicas de Boas Práticas de Alimentação e Qualidade no Atendimento; à escola de gastronomia Oficina de Chefs para a 
execução de aulas para montagem de pratos, e ainda palestras sobre cultura e gastronomia com especialistas nesta área. Todas as ações relacionadas à capacitação ocorreram durante todo o ano, sendo algumas prévias à chegada do circuito na cidade e algumas ao longo do ano. As etapas do Circuito Delícias de Pernambuco foram definidas pelo Sebrae, obedecendo aos seguintes passos:

1. Lançamento do Circuito Delícias de Pernambuco em Recife;

2. Definição do calendário para cada município;

3. Inscrição das empresas e venda de cotas de patrocínio em cada município;

4. Inicio do programa de capacitação das empresas em cada município;

5. Realização do festival;

6. Auditoria e resultados do festival.

Esta foi a ordem adotada nos municípios com exceção dos dois festivais de Recife, que por tradição, operam utilizando outra metodologia operacional. Para outros festivais foi constituída uma equipe capitaneada pela unidade de projetos do Sebrae com os escritórios em cada município e uma empresa terceirizada contratada para venda e operacionalização destes festivais.

Para participar do circuito, o restaurante deveria criar um prato e uma sobremesa exclusivos, de acordo com o tema sugerido ou acordado entre os participantes de cada festival, e que, obrigatoriamente remeteriam, às características culturais locais, como também aos produtos nativos e típicos da região. Houve um estímulo também para marcação de preços convidativos, pois os festivais tinham também intenções comerciais.

Os festivais aconteceram nas datas apresentadas abaixo. Em cada município houve uma abertura solene do festival com a apresentação dos pratos do festival e a presença de autoridades, dos participantes e patrocinadores do evento. $\mathrm{Na}$ ocasião eram entregues certificados de participação aos restaurantes e chefes que elaboraram as receitas.

1. Caruaru - Show gastronômico do agreste - De 19 a 28 de maio de 2006;

2. Recife Sabor - De 20 de julho a 20 de agosto de 2006; 
3. Garanhuns - Festival gastronômico sabor das flores - De 17 a 26 de agosto de 2006;

4. Serra Talhada e Triunfo - Festival gastronômico da culinária Caprina e Ovina - de 01 a 10 de setembro de 2006;

5. Gravatá - Festival Gastronômico de Gravatá - De 21 a 30 de setembro de 2006;

6. Ipojuca - Porto do Sabor - De 05 a 15 de outubro de 2006;

7. Recife - Festival Gastronômico de Pernambuco - De 15 a 27 de outubro de 2006;

8. Petrolina - Festival de gastronomia Frutos do Vale - De 03 a 11 de novembro de 2006.

Durante os dias do festival os pratos criados pelos cozinheiros e chefes eram divulgados através de folder e disponibilizados no cardápio dos restaurantes. $\mathrm{Na}$ entrada de cada restaurante era afixado um banner com a foto e o título da receita do prato. O festival também foi divulgado na mídia local através de comerciais de rádio e outdoors.

\subsection{O roteiro dos acontecimentos}

Para a avaliação do Circuito Delícias de Pernambuco foi realizada uma pesquisa de caráter empírico-analítica tratando o desenvolvimento do circuito como estudo de caso. O trabalho de campo foi realizado através de entrevistas orientadas e não orientadas e os resultados de vendas disponibilizados pela unidade de projetos do Sebrae-PE em Recife Estas foram as principais fontes para mensurar os resultados do Circuito Delícias de Pernambuco.

As entrevistas foram divididas em dois momentos. No primeiro momento versavam sobre a verificação de potencialidades turísticas no município e o registro de produtos e preparações gastronômicas e num segundo momento feitas após a realização do evento tendo como principais questionamentos a satisfação dos restaurantes e patrocinadores de participar do evento e dos promotores de dar continuidade ao evento no ano seguinte.

As entrevistas prévias geraram um mapeamento dos principais produtos alimentícios produzidos e consumidos no município. Este mapeamento foi utilizado para a construção de um inventário culinário preliminar de cada localidade e para a preparação de um texto de sensibilização e outro texto promocional, além de palestras. Vale lembrar que a proposta do mapeamento foi a de não limitar as entrevistas e pesquisas à culinária, mas tentar mesclar o 
fazer comida com a cultura popular e com as manifestações do fazer arte em cada localidade. Por isso foram entrevistadas pessoas ligadas ao comércio, representantes administrativos dos municípios e funcionários e proprietários dos restaurantes participantes.

Quadro 1 - Entrevistas Mapeamento Cultural

\begin{tabular}{|c|c|c|c|}
\hline LOCAL & $\begin{array}{c}\text { Data das } \\
\text { Entrevistas }\end{array}$ & Lugares Visitados para Entrevistas & $\mathrm{N}^{\circ}$ \\
\hline Gravatá & $22 / 08$ e $23 / 09 / 06$ & $\begin{array}{l}\text { Restaurantes participantes } \\
\text { Feira de Negócios Sebrae } \\
\text { Feira semanal do centro da cidade } \\
\text { Secretaria de Turismo }\end{array}$ & 23 \\
\hline $\begin{array}{l}\text { Serra Talhada e } \\
\text { Triunfo }\end{array}$ & $30 / 08$ a $02 / 09 / 06$ & $\begin{array}{l}\text { Restaurantes participantes } \\
\text { Convento Santa Elisabeth } \\
\text { Feira de produtos orgânicos } \\
\text { Colégio Irmãos Salesianos } \\
\text { Cachaçaria Triunfo e Mercadinhos } \\
\text { Museu do Cangaço/ Barracas na Festa da Padroeira } \\
\text { Hotel Sesc - Restaurante Caretas }\end{array}$ & 22 \\
\hline $\begin{array}{ll}\text { Porto } & \mathrm{de} \\
\text { Galinhas } & \end{array}$ & $\begin{array}{l}12 \text { e } 13 / 09 / 06 \\
28 / 09 / 06\end{array}$ & $\begin{array}{l}\text { Restaurantes participantes } \\
\text { Engenho Canoas - Outeiro } \\
\text { Vila de Porto de Galinhas - praia e empresários } \\
\text { Maracaípe - praia } \\
\text { Nossa Senhora do Ó }\end{array}$ & 25 \\
\hline Petrolina & 19 a $21 / 09 / 06$ & $\begin{array}{l}\text { Restaurantes participantes } \\
\text { Vinícola Garzieira e Rio Sol } \\
\text { Senai - Escola Técnica - Engenharia de Alimentos. } \\
\text { Restaurantes da Orla de Petrolina. } \\
\text { Shopping Center de Petrolina } \\
\text { Bodódromo / Galinhódromo } \\
\text { Mercados e Atelier Ana das Carrancas } \\
\text { Atelier de artesãos }\end{array}$ & 28 \\
\hline Garanhuns & 10 e $11 / 07 / 06$ & $\begin{array}{l}\text { Restaurantes participantes } \\
\text { Casa de Farinha- Povoado Castainho } \\
\text { Licores Caseiros (D.Iraildes) } \\
\text { Mosteiro de São Bento } \\
\text { Chocolateria } 7 \text { Colinas (fábrica e loja) } \\
\text { Casas de Artesanato }\end{array}$ & 26 \\
\hline Caruaru & $02 / 09$ & $\begin{array}{l}\text { Feira de Caruaru } \\
\text { Shopping Center Caruaru } \\
\text { Mercados de confecções de moda } \\
\text { Alto do Moura }\end{array}$ & 15 \\
\hline
\end{tabular}

Mas tantas entrevistas e este mapeamento não seriam de todo interessantes se os achados ficassem só no papel e fossem apresentados apenas no final do evento. Como o circuito tinha entre os objetivos ampliar a visibilidade da gastronomia pernambucana de uma forma 
dinâmica, resolveu-se divulgar os levantamentos a cada etapa prévia do circuito em cada localidade. Os textos contendo os primeiros achados foram divulgados quando da visita dos cozinheiros e proprietários à Oficina de Chefs - local onde aconteceram os treinamentos práticos de cozinha e a organização das receitas. $\mathrm{Na}$ ocasião foi divulgada uma lista com os principais pontos turísticos a serem explorados pelos chefes para nomear seus pratos, além de uma palestra de sensibilização para os donos de restaurantes e suas brigadas, para que ao trabalhar seus pratos utilizassem e valorizassem os produtos e personalidades da região, bem como para que entendessem a importância da gastronomia e da qualidade dos serviços para o turismo.

Após a realização dos festivais em cada município foi feita a segunda bateria de entrevistas com alguns restaurantes participantes em reuniões promovidas pela equipe dos promotores do evento Abrasel e Sebrae-PE e por telefone. Os dados de Recife não foram apresentados no quadro 2 por utilizarem uma metodologia diferente de aferição de venda. Desta forma foram obtidas as seguintes informações:

Quadro 2 - Pratos Vendidos

\begin{tabular}{|l|l|l|}
\hline \multicolumn{1}{|c|}{ Município } & \multicolumn{1}{|c|}{ Número de restaurantes } & Número de pratos vendidos \\
\hline Caruaru & 15 & 60 \\
\hline Garanhuns & 08 & 1.241 \\
\hline Serra Talhada e Triunfo & 09 & 260 \\
\hline Gravatá & 14 & 764 \\
\hline Porto de Galinhas & 15 & 685 \\
\hline Petrolina & 14 & 505 \\
\hline
\end{tabular}

Através do quadro 2, verifica-se a maior venda ocorrida em Garanhuns seguida de Porto de Galinhas - dois pólos já consagrados pelo turismo de inverno e verão respectivamente. Como este foi o primeiro evento sistematizado na área de gastronomia, os resultados de vendas não têm parâmetros para comparações, mas segundo entrevistados os resultados foram significativos para a divulgação institucional do restaurante.

Quanto ao número de pessoas treinadas, 290, apresentado no quadro 3 nas áreas de segurança alimentar, práticas culinárias, palestras culturais e cursos para garçons, verificou-se que atenderam a parcialmente a quantidade previamente estabelecida pelas empresas parceiras 
como Senac, Abrasel, Sebrae e Oficina de Chefs no projeto do festival. Os cursos previam pelo menos um representante de cada estabelecimento participante do circuito e alguns casos esta representação não ocorreu como em Caruaru, Garanhuns e Petrolina.

Quadro 3 - Capacitação

\begin{tabular}{|l|l|l|l|l|}
\hline Curso /município & $\begin{array}{l}\text { Curso } \\
\text { garçom } \\
\text { Participantes }\end{array}$ & $\begin{array}{l}\text { Curso } \\
\text { Segurança } \\
\text { alimentar } \\
\text { Participantes }\end{array}$ & $\begin{array}{l}\text { Palestra cultural } \\
\text { Participantes }\end{array}$ & $\begin{array}{l}\text { Curso práticas } \\
\text { culinárias } \\
\text { Participantes }\end{array}$ \\
\hline Caruaru & Nenhum & Nenhum & Nenhum & 15 \\
\hline Garanhuns & 08 & Nenhum & 08 & 13 \\
\hline $\begin{array}{l}\text { Serra Talhada e } \\
\text { Triunfo }\end{array}$ & 09 & 08 & 22 & 09 \\
\hline Gravatá & 14 & 26 & 14 & 16 \\
\hline Porto de Galinhas & 15 & 24 & 15 & 15 \\
\hline Petrolina & 14 & 16 & 11 & 18 \\
\hline
\end{tabular}

O livro "Circuito Delícias de Pernambuco - Do litoral ao Sertão", também um dos pontos de perpetuação do circuito foi produzido, e consta inclusive, da bibliografia deste estudo. No livro estão expressas todas as fotos dos pratos e as receitas dos festivais participantes incluindo os do Recife Sabor e do Festival Gastronômico de Pernambuco, que como já citado utilizam metodologia de operação diferenciada, impossibilitando comparativo de dados para este estudo. Alguns depoimentos foram obtidos e registrados no livro generalizando a avaliação do circuito, mas são de suma importância para o registro e avaliação do evento, pois partiram dos promotores, restauranteiros e operadores do circuito.

Através dos resultados de vendas, números de pessoas qualificadas e o registro dos resultados do mapeamento cultural e da produção gastronômica de cada restaurante traduzido em fotos e receitas no livro acima citado, pode-se aferir alguns resultados do Circuito Delicias de Pernambuco. 


\section{Considerações Finais}

As etapas de planejamento do Circuito Delicias de Pernambuco foram cumpridas através da realização dos oito festivais que compuseram o evento. A realização desta primeira edição proporcionou o inicio dos estudos da potencialidade turística da gastronomia em municípios pernambucanos. O caso Circuito Delícias de Pernambuco demonstrou através da venda de pratos, capacitação de funcionários, entrevistas junto aos proprietários dos restaurantes e promotores e ainda da publicação de livro inventário com as fotos e receitas da modernidade gastronômica pernambucana, que o circuito tem potencialidades de ser realizado novamente e de constituir elemento significativo para o desenvolvimento turístico do interior do estado.

O circuito marcou sem a menor dúvida, o início do resgate do acervo da alimentação pernambucana para o estabelecimento de um lugar na história e nas tradições familiares e sobretudo, para proporcionar atração cultural e desenvolvimento de novas localidades turísticas. O desenvolvimento de novos pratos para a participação no circuito promoveu positivamente uma busca pelos produtos locais e por preparações familiares. O trabalho dos chefes e cozinheiros foi cuidadoso na escolha de produtos locais que pudessem representar a sua cidade e ao mesmo tempo foi primoroso na transformação dos pratos locais para uma nova estética de apresentação exigida pela gastronomia moderna, assim registrados no livro "Circuito Delícias de Pernambuco - Do Litoral ao Sertão".

Entre os resultados observados e constatados através das entrevistas com participantes está a falta de um projeto de marketing específico para a divulgação do festival com antecedência nas cidades e principalmente, para as operadoras de turismo, que poderiam vincular o festival a promoções e a outras atrações e ainda promover o deslocamento de visitantes de cidades vizinhas durante o evento - o que não ocorreu. De acordo com os participantes, a chegada de visitantes de outras cidades durante o festival foi insignificante, sendo este desfrutado pelos residentes. As cidades em que houve a maior venda de pratos durante os dias do festival local foram Garanhuns e Porto de Galinhas que já são consagrados destinos turísticos em Pernambuco - Garanhuns no inverno, quando acontece o festival de inverno com atrações e shows e Porto de Galinhas no verão, ou seja, na alta estação, que vai de agosto a março. Portanto, o circuito parece não ter sido um motivador para o deslocamento, mas por outro lado, um componente importante para o fortalecimento do turismo na localidade.

As atividades de capacitação nos estabelecimentos participantes contribuíram para a 
motivação das equipes, porém pelo mesmo motivo acima citado da divulgação, os treinamentos foram comunicados com pouca antecedência provocando problemas operacionais nos restaurantes, que disponibilizaram os seus funcionários sem prévia sensibilização ou em alguns casos, não houve tempo hábil para a participação dos funcionários no plano de treinamento como no caso de Caruaru.

O ideal é que o Circuito Delícias de Pernambuco se torne um pretexto para conhecer as cidades participantes, a sua gastronomia, história, pontos turísticos, artesanato e outros aspectos culturais. Para tanto, é necessário um estudo complementar para o levantamento de atrações naturais e artificiais de cada localidade e como colocado neste estudo, o aprimoramento dos meios de hospedagem para o acolhimento completo do visitante através da capacitação dos operadores de hotéis e pousadas. Só assim, o Circuito Delícias de Pernambuco poderia se tornar uma atração para constituição de produtos turísticos para cada município participante e um evento importante comercialmente para o segmento de restaurantes.

Para a próxima edição a elaboração de uma pesquisa organizada junto aos restauranteiros e visitantes para comprovação do motivo da participação no festival seria importante. A falta deste instrumento, inclusive, limitou um aprofundamento deste estudo. Finalmente, constatouse que o circuito ainda não é um fator motivador para o deslocamento de pessoas em busca das novidades gastronômicas, mas é potencial componente de produtos turísticos que por ventura forem formatados para a promoção do turismo no interior de Pernambuco e valorização do patrimônio gastronômico e cultural.

Vale ressaltar ainda, que o Circuito Delícias de Pernambuco está salvaguardando os sabores pernambucanos e orientando o turismo como atividade para o desenvolvimento do interior do estado através de capacitação para a hospitalidade.

\section{Referências}

ABRASEL. S/D. Disponível em: < http://www.brasilsabor.com.br>. Acesso em 20 abr 2007.

ALGRANTI, Marcia. 2006. Conversas na cozinha. Rio de Janeiro: Senac Nacional.

BASÍLICO . S/D. Disponível em: < http:// basilico.uol.com.br/cgi-bin/reportbasilico/viajar/viajar>. Acesso em 20 mar 2007. 
CASCUDO, Luis da Câmara. 2004. História da alimentação no Brasil. Luiz Câmara Cascudo. 3 edSão Paulo: Global.

CARNEIRO, Henrique. 2003. Comida e Sociedade: uma história da alimentação. Rio de Janeiro: Campus.

FERNÁNDEZ-ARMESTO, Felipe. 2004. Comida: uma história. Tradução de Vera Joscelyn. Rio de Janeiro: Record.

FRANCO, Ariovaldo. 2001. De caçador a gourmet: uma história da gastronomia. São Paulo: Editora Senac.

GREGSON, Paul William. 2005. Festival Gastronômico: aspectos históricos, práticos e administrativos de um evento segmentado. Barueri, SP: Minha Editora.

LEAL, Maria Leonor de Macedo. 1998. A História da Gastronomia. Rio de Janeiro. Ed Senac Nacional.

REVISTA ÉPOCA. S/D. Disponível em: <http://revistaepoca.globo.com/Epoca>. Acesso em: 15 abr 2007.

RIBEIRO, Carlos Manoel Almeida. 2006. Gastronomia: uma história e cultura. São Paulo: Editora Hotec.

ROMIO, Eda. 2000. Brasil 1500/2000: 500 anos de Sabor. São Paulo: ER Comunicações.

SANTOS, C. R. A. dos. 2005. A alimentação e seu lugar na História: Questões \& Debates. Curitiba: Editora UFPR, n. 42, p. 11-31.

SAVARIN, Brillat. 1995. A Fisiologia do Gosto. Tradução: Paulo Neves. São Paulo: Companhia das Letras.

SENAC, DN. 1988. A história da gastronomia. Maria Leonor de Macedo Soares Leal. Rio de Janeiro: Ed. Senac Nacional.

SERVIÇO BRASILEIRO DE APOIO AS MICRO E PEQUENAS EMPRESAS DE PERNAMBUCO. 2006. Do litoral ao sertão 2006. Livro de receitas dos festivais gastronômicos participantes do Circuito Delícias de Pernambuco/Sebrae/PE. Textos: Isabella Jarocki. Recife.

SPANG, Rebecca L. 2003. A invenção do restaurante. Trad. Cynthia Cortes e Paulo Soares. Rio de Janeiro: Record, 391p.

SUAUDEAU, Laurent. 2006. Cartas a um jovem chef.

TELLET, Pierre. 2005. História das cozinhas faraônicas: a alimentação do Egito Antigo. Tradução: Olga Cafalcchio. São Paulo: Editora Senac.

\section{Recebido em: 15/02/2008 (1 ${ }^{\mathrm{a}}$ versão) $09 / 04 / 2008$ ( $2^{\mathrm{a}}$ versão) Aprovado em: 19/12/2008}

